\title{
Rheological and physical analysis of oil-water emulsion based on enzymatic structured fat
}

\author{
Małgorzata Kowalska $^{1} \cdot$ Anna Krztoń-Maziopa ${ }^{2} \cdot$ Monika Babut $^{1} \cdot$ Paulina Mitrosz $^{1}$
}

Received: 15 April 2020 / Revised: 26 June 2020 / Accepted: 3 August 2020 / Published online: 12 August 2020

(C) The Author(s) 2020

\begin{abstract}
Structured triacylglycerols play an important role in determining the functional properties of fat-based emulsion products. The aim of the study was to evaluate the physical properties of the emulsion systems manufactured on the basis of enzymatically modified rabbit fat with pumpkin seed oil in the presence of $s n-1,3$ regioselective lipase. Emulsions containing variable contents of thickener and variable fat ratios were analyzed for rheological behavior and particle size changes during storage, and their stability was assessed using the Turbiscan test. The results showed that the emulsion containing the majority of rabbit fat and $1 \mathrm{wt} \%$ of carboxymethylcellulose was characterized by the highest stability. On the other hand, the emulsions containing higher amounts of pumpkin seed oil in a fatty base characterized the lowest resistance to destabilization processes. The research confirmed the possibility of producing structured fat which can be the basis for new emulsion systems proposed as a food, cosmetic, and pharmaceutical product.
\end{abstract}

Keywords Structured lipids $\cdot$ Emulsions $\cdot$ Stability of emulsion $\cdot$ Rheology

\section{Introduction}

Triacylglycerols play a key role in determining the functional properties of fat-based food or cosmetic products. The physical properties of the fat crystal network formed by triacylglycerols (TAG) determine the functional properties of these products, such as their texture, plasticity, and the mouth feel (De Graef et al. 2012). The changes in the TAG composition cause by different modifications can have a big impact on the crystallization and the further structure development of the fats. Over last time, fat modification is frequently aimed as a means to develop more healthy fat products with better crystallizations and texture. The most popular modifications applied to form new fats are blending, hydrogenation, interesterification, and fractionation. The method that allows obtaining fat with

Małgorzata Kowalska

mkowalska7@vp.pl

1 Faculty of Chemical Engineering and Commodity Science, Kazimierz Pulaski University of Technology and Humanities, Radom, Poland

2 Faculty of Chemistry, Warsaw University of Technology, Warsaw, Poland programmed properties while remaining in harmony with the natural environment is enzymatic interesterification. Lipases show high selectivity including stereo-selectivity and give products of high purity and improve its structure and quality (Kraai et al. 2008). Research on structured lipids is growing rapidly, including partly acylglycerols as monoacylglycerol (MAG) and diacylglycerol (DAG), due to their nature as a popular emulsifier. Besides, MAG and DAG can also improve the physical and functional properties of lipids, such as crystallization, melting points, solid fat content, texture, rheology, and polymorphism (Kowalska et al. 2018; Subroto 2020).

Emulsions are colloidal systems, which consist of a dispersion of dispersed phase in the continuous phase (Tzoumaki et al. 2011). From a thermodynamics point of view, nanoemulsions, microemulsions, and macroemulsions are unstable systems (Anton and Vandamme 2011). These systems tend to phase separation during storage, due to the presence of destabilizing mechanisms, i.e., increase in droplet size (Ostwald ripening or coalescence), drop aggregation (flocculation), or gravity separation (creaming, sedimentation) (McClements and Rao 2011). Conventionally, emulsions are stabilized by the introduction of emulsifiers, i.e., molecular surfactants absorbed in the oil/water interface during homogenization, creating spherical and electrostatic protection for emulsified drops (Tang et al. 2015). Furthermore, substances 
used to ensure the adequate kinetic stability of dispersion systems are ripening inhibitors, texture modifiers, and binders. Ripening inhibitors (compounds preventing Ostwald ripening) are practically insoluble in water, while the binding agents are hydrophobic components, which ward off gravitational separation (Lim et al. 2015). Another group of compounds affecting reduction of the destabilization changes occurring in emulsions are texture modifiers-substances which increase the viscosity of the system, delaying or preventing the movement of droplets (Piorkowski and McClements 2013). The selection of an appropriate stabilizer is an overriding factor in determining the stability during the entire storage period of the dispersion system, which forms specific physicochemical properties of an emulsion. Besides, the lower the content of fat in the emulsion, the more important the role of the thickener or emulsifier to keep good stability of the emulsion (Zou and Akoh 2013). Generally, physicochemical properties, i.e., rheology and particle distribution optical and sensory properties, of the emulsions also depend on the properties of the droplets, and precisely on their size (Kowalska et al. 2014). Emulsions characterized by the presence of droplets similar in size are referred to as a monodisperse, while systems containing droplets in a wide range of particle sizes are called polydisperse. The structure of colloidal systems can change over time, which is related to the size changes or migration of droplets. The result of these changes is a decrease of stability. Knowledge about the droplet size and its distribution of an emulsion is extremely important from the manufacturer's point of view because it provides information about particle size characteristics as well as the possibility of the destabilization process and its character (Kowalska 2016).

The aim of the study was to introduce the interesterified rabbit fat with pumpkin seed oil into the emulsion as an oil phase. Vegetable oils or mixed oils are commonly used in the cosmetics and pharmaceutical industries as oil phases of emulsions. In the food industry, the oil phase may be interesterified fats containing animal fat, i.e., lard, beef tallow, or palm oil fractions. Until now, rabbit fat was not a research object in the context of the interesterification process. Thus, enriching it in the process of enzymatic interesterification with unsaturated fatty acids derived from seed oil for days makes it highly attractive. The use of such fat in model emulsion systems is a new approach.

\section{Materials and methods}

\section{Materials}

- Fat phase of the emulsion which was prepared on the basis of the following components: rabbit fat (RF) (obtained from private grocery stores or large discount chains), characterized by the main following acids (FA): palmitic acid
C16:0 - 34.4\%, oleic acid C18:1 9c-25.7\%, linoleic acid C18:2 all cis-16.1\%, stearic acid C18:0-5.5\%, palmitoleic acid $\mathrm{C} 16: 19 \mathrm{c}-5.2 \%$, myristic acid $\mathrm{C} 14: 0-$ $3.3 \%$, and cold-pressed pumpkin seed oil (PSO) (Oleofarm s.c., Wrocław, Poland), contained the main following fatty acids: linoleic acid C18:2 all cis-46.5\%, oleic acid $\mathrm{C} 18: 19 \mathrm{c}-33.9 \%$, palmitic acid $\mathrm{C} 16: 0-$ $11.4 \%$, stearic acid $\mathrm{C} 18: 0-6.3 \%$;

- lipase, immobilized on immobead 150 from Rhizomucor miehei, $\geq 300 \mathrm{U} / \mathrm{g}$ (Sigma Aldrich, the Netherlands);

- distilled water;

- carboxymethylcellulose (CMC) (Pronicel Sp. z o.o.);

- sodium benzoate (SB)(POCh).

\section{Methods}

\section{Enzymatic interesterification reactions}

The blends of rabbit fat and pumpkin seed oil in a weight ratio of 75:25, 60:40, 50:50, 40:60, and 25:75 were mixed in flasks and then placed into a shaker equipped with a water bath (Elpin-Plus, Poland). The prepared blends were thermostated for $10-15 \mathrm{~min}$ at $60 \pm 0.5^{\circ} \mathrm{C}$. Thereafter, the enzyme catalyst, $s n-1,3$ regioselective lipase, in the amount of $5 \mathrm{wt} \%$ (in relation to fat blend mass) and water in the amount of $22 \mathrm{wt} \%$ (in relation to the enzymatic preparation) were added into the flasks. The use of enzymatic catalysis was, inter alia, dictated by the production of structured lipids from hemp oil and rabbit fat and allowed to obtain a sufficient amount of MAG and DAG which was an emulsifier in the subsequent emulsion system.

Next, the flasks containing the prepared mixtures were shaken for $6 \mathrm{~h}$. The reaction was stopped by removing (hot filtration) the enzyme from the reaction mixture.

\section{Formulation of emulsions}

The aqueous phase was received by dispersing a suitable amount of carboxymethylcellulose (used as a thickener) in distilled water for $1 \mathrm{~min}$. The exact quantities of CMC used for preparation of emulsions are listed in Table 1. The second phase constituting $30 \% \mathrm{w} / \mathrm{w}$ of the emulsion system was the modified fat blend containing rabbit fat and pumpkin seed oil in the given proportions and enough emulsifiers resulting from the interesterification process (Kowalska et al. 2019). Both phases were mixed at a temperature of $55-60{ }^{\circ} \mathrm{C}$. Homogenization of those phases was achieved using a mechanical homogenizer equipped with a S18G-19G dispersing head (T18 digital ULTRA-TURRAX, IKA, China). Each emulsion was homogenized for $4 \mathrm{~min}$ at a constant speed of $18,000 \mathrm{rpm}$, then cooled down to room 
Table 1 Emulsion formulations

\begin{tabular}{|c|c|c|c|c|c|c|c|c|c|c|c|c|c|c|c|}
\hline \multirow{2}{*}{$\begin{array}{l}\text { Components } \\
\text { (wt } \%)\end{array}$} & \multicolumn{15}{|c|}{ Emulsions } \\
\hline & E1 & E2 & E3 & E4 & E5 & E6 & E7 & E8 & E9 & E10 & E11 & E12 & E13 & E14 & E15 \\
\hline $\mathrm{RF} / \mathrm{PSO}$ & \multicolumn{3}{|c|}{$22.5 / 7.5$} & \multicolumn{3}{|c|}{$18.0 / 12.0$} & \multicolumn{3}{|c|}{$15.0 / 15.0$} & \multicolumn{3}{|c|}{$12.0 / 18.0$} & \multicolumn{3}{|c|}{$7.5 / 22.5$} \\
\hline CMC (0.6) & \multicolumn{3}{|l|}{$\mathbf{V}$} & \multicolumn{3}{|l|}{$\mathbf{V}$} & \multicolumn{2}{|l|}{$\mathbf{V}$} & & \multicolumn{2}{|l|}{$\mathbf{V}$} & & \multicolumn{2}{|l|}{$\mathbf{V}$} & \\
\hline CMC (0.8) & \multirow{2}{*}{\multicolumn{2}{|c|}{$\mathbf{V}$}} & & \multirow{2}{*}{\multicolumn{2}{|c|}{$\mathbf{V}$}} & & \multirow{2}{*}{\multicolumn{2}{|c|}{$\mathbf{V}$}} & & \multicolumn{3}{|c|}{$\mathbf{V}$} & \multicolumn{3}{|c|}{$\mathbf{V}$} \\
\hline CMC (1.0) & & & $\mathbf{V}$ & & & $\mathbf{V}$ & & & $\mathbf{V}$ & & & $\mathbf{V}$ & & & $\mathbf{V}$ \\
\hline SB & \multicolumn{15}{|l|}{0.3} \\
\hline Water & \multicolumn{15}{|c|}{ To 100.0} \\
\hline
\end{tabular}

$\mathbf{V}$ shows an emulsion containing the indicated amount of thickener. $R F$ rabbit fat, $P S O$ pumpkin seed oil, $C M C$ carboxymethylcellulose, $S B$ sodium benzoate

temperature at which the preservative (sodium benzoate in amount of $0.3 \mathrm{wt} \%$ ) was added. Total weight of each emulsion after preparation was $100.0 \mathrm{~g}$.

\section{Emulsion stability-Turbiscan test}

The long-term stability of all emulsion systems was evaluated using Turbiscan Lab Expert (Formulaction, L'Union, France). Transmittance and backscattering variations were carried out using a pulsed, near-infrared LED at a wavelength of $880 \mathrm{~nm}$. The device is used to analyze the stability/instability of dispersions (emulsions, suspensions, and foams) with a wide range of concentration and particle size, and to measure the average diameter of particles without having to dilute the sample (Instruction Turbiscan Lab 2013). The principle of its operation is based on measuring the backscattering light stream and the transmission through the vessel containing emulsions. According to the procedure, emulsions were placed in special cylindrical cells up to a height of $55 \mathrm{~mm}$, then transferred to the apparatus and scanned along the height. The obtained profiles reflecting the state of the tested emulsions mean the curves of the percentage of the backscattered light as a function of the height of the vial in which the emulsion is located. The first measurement was carried out on the day of emulsion preparation, and the measurements were repeated every 34 days during the 1-month storage period at a room temperature. The obtained results are presented as the variances of the backscattered light profile $\triangle \mathrm{BS}$ (delta backscattering) and Turbiscan Stability Index (TSI).

TSI was obtained according to the equation $(\mathrm{Xu}$ et al. 2016):

$\mathrm{TSI}=\sum_{i} \frac{\sum_{\mathrm{h}}\left|\operatorname{scan}_{i}(\mathrm{~h})-\operatorname{scan}_{i-1}(\mathrm{~h})\right|}{H}$

where $\operatorname{scan}_{\mathrm{i}}(\mathrm{h})$ is the mean backscattering for time $(i)$ of measurement, $\operatorname{scan}_{\mathrm{i}-1}(\mathrm{~h})$ is the average backscattering for the $i$-1 time of measurement, and $H$ is the height of sample.
The obtained data from the Turbiscan test allowed to calculate the average particle size of the dispersed phase of each emulsion.

\section{Droplet size of the emulsion}

Droplet size was measured by an optical microscope (Genetic Pro Trino, Delta Optical, Poland) connected to a digital camera (DLT Cam PRO, Delta Optical, Poland) at $\times 10$ magnification and $\times 40$ objective without polarization of light after $24 \mathrm{~h}, 1-4$ weeks from manufacturing. The microphotographs of the emulsions were taken after transferring the samples on the microscope slide and then covering them with coverslip. The size distribution of measured droplets was presented as the change of an average particle size during storage of emulsions.

\section{Rheological measurement}

Rheological studies were carried out using the Physica MCR 301 rheometer equipped with a parallel plate measuring geometry (50-mm diameter and 1-mm gap). Measurements were carried out at constant temperature $20 \pm 0.02^{\circ} \mathrm{C}$, controlled by a built-in precise Peltier unit. Rheological tests in a controlled shear stress (CSS) mode were performed to reveal the shear thinning behavior of the prepared emulsions. Viscoelastic properties of the investigated materials were examined with a small-strain amplitude oscillatory experiment at constant angular frequency (1 rad/s) and frequency dependencies of storage $\left(\mathrm{G}^{\prime}\right)$ and loss $\left(\mathrm{G}^{\prime \prime}\right)$ moduli recorded at constant strain amplitude $(0.1 \%)$ in the angular frequency range $0.1-100 \mathrm{rad} / \mathrm{s}$.

\section{Results and discussion}

Turbiscan Lab Expert is a device allowing to determinate the stability of opaque and concentrated dispersion systems. It is 
Fig. 1 Mean delta backscattering values (\%) for emulsions E1-E15 during storage period

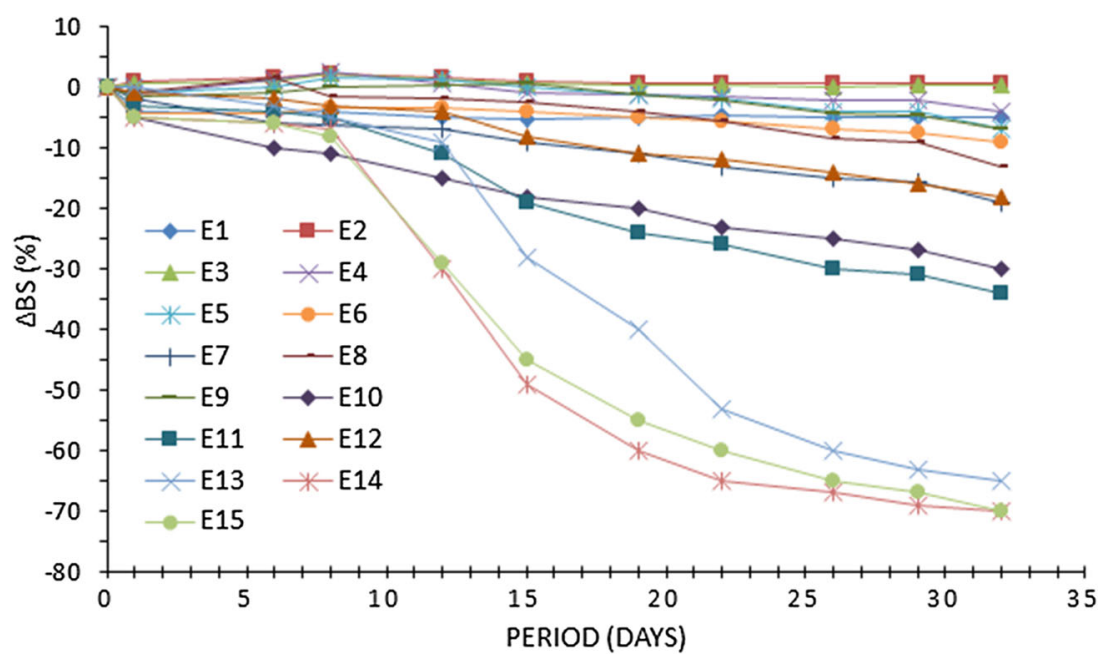

also a valuable tool for detection of small destabilizing phenomena occurring much earlier than they are noticeable at a macroscopic scale (Liu et al. 2011). The measurement principle is based on a detection of migration or particle size change (coalescence) of a dispersed phase over time, which leads to a variation of backscattering and transmission of light intensity (Celia et al. 2009). The modification of the intensity of a backscattering light intensity is graphically represented in the form of negative (backscattered light decrease) or positive (backscattered light increase) peaks (Paolino et al. 2011). If the positive or negative change of the backscattered light profile is within $\pm 2 \%$, then the system is considered stable (no migration or particle size change). Variations greater than $10 \%$ indicate instability of the formulation (Celia et al. 2009). In addition, it provides comprehensive information in the context of occurring destabilization processes (Sztukowski and Yarranton 2005).

The results of the stability measurements of the emulsion systems presented as delta backscattered light profiles during the 1-month storage period are shown in Fig. 1. Generally, the emulsions from the very beginning showed changes of the intensity of backscattered light intensity. The highest difference in $\triangle \mathrm{BS}$ values after the storage period was observed for emulsions E13, E14, and E15, where this value decreased by over $60 \%$ after 20 days of storage. In these three cases, the observed instability concerned two overlapping mechanisms: droplet coalescence and particle migration (Wiśniewska et al. 2014). Lower dynamics of the changes was observed for emulsions containing higher animal fat content. The difference up to the 22nd day of storage did not exceed $30 \%$. After this time, a decrease in backscattered light intensity was observed, although the changes did not exceed $35 \%$ throughout the storage period. According to McClements (2007), in the E10-E15 systems, the coalescence process probably occurred, in which oil-in-water emulsions lead to the formation of an oil layer in the upper part of the emulsion, due to the oiling-off process. Evaluating the stability of individual emulsions, it was also found that in emulsions E2 and E3, containing the predominant amount of rabbit fat (75\%), the destabilization processes during the 1-month storage period (Fig. 1) were not observed. The maximum difference of BS values was $0.7 \%$ and $0.15 \%$, respectively, for E2 and $\mathrm{E} 3$, which confirms the correct stability of the dispersion systems.

The Turbiscan Stability Index determines the kinetics of destabilization processes during sample storage; the higher the TSI value, the greater the instability of the emulsion (Wiśniewska 2010). In order to determine the effect of a variable ratio of RF and PSO and the viscosity modifier content on the stability, the value of the TSI parameter was determined (Fig. 2). The presented data indicated that the highest kinetics of changes was noted for emulsions E14 and E15, and no effect of the amount of viscosity modifier was noted. This also confirmed that emulsions containing the predominant part of vegetable oil exhibit greater system instability. The opposite situation was observed for emulsion E3, for which the value of the TSI parameter was the lowest (Fig. 2). A higher value of the TSI was observed for the emulsion E1, but the invariability of its value confirmed the absence of destabilization changes in this system. However, on the basis of the mentioned data, it

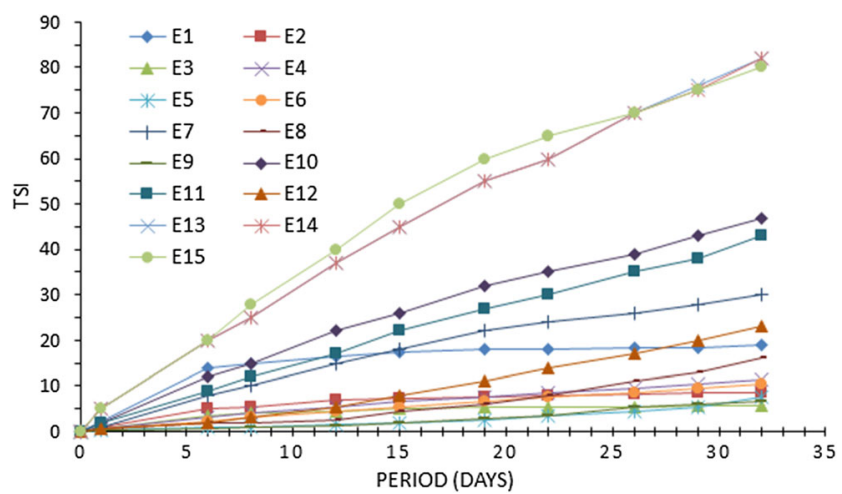

Fig. 2 Turbiscan Stability Index of emulsions E1-E15 stored at room temperature 
Table 2 Average particle size of emulsions $24 \mathrm{~h}$, and 1, 2, 3, and 4 weeks after preparation, and the percent of increase of average particle size during the storage period

\begin{tabular}{|c|c|c|c|c|c|c|}
\hline \multirow[b]{2}{*}{ Emulsions } & \multicolumn{6}{|c|}{ Average particle size $(\mu \mathrm{m})$ after } \\
\hline & $24 \mathrm{~h}$ & 1 week & 2 weeks & 3 weeks & 4 weeks & $\begin{array}{l}\text { Increase of average } \\
\text { particle size after } 4 \\
\text { weeks of storage }(\%)\end{array}$ \\
\hline E1 & 4.7 & 4.7 & 4.8 & 4.8 & 5.0 & 6 \\
\hline E2 & 4.2 & 4.2 & 4.3 & 4.4 & 4.5 & 6.7 \\
\hline E3 & 4.2 & 4.2 & 4.3 & 4.4 & 4.4 & 4.5 \\
\hline $\mathrm{E} 4$ & 8.0 & 8.2 & 8.4 & 9.2 & 9.4 & 14.9 \\
\hline E5 & 7.3 & 7.6 & 7.7 & 8.4 & 8.5 & 14.1 \\
\hline E6 & 7.2 & 7.3 & 7.6 & 8.5 & 9.1 & 20.9 \\
\hline E7 & 10.5 & 10.8 & 10.9 & 11.3 & 11.8 & 11.0 \\
\hline E8 & 8.4 & 9.1 & 9.6 & 9.8 & 9.9 & 15.2 \\
\hline E9 & 5.9 & 6.0 & 6.3 & 6.6 & 6.8 & 13.2 \\
\hline E10 & 14.8 & 14.9 & 15.5 & 16.8 & 17.4 & 14.9 \\
\hline E11 & 13.5 & 13.9 & 14.1 & 14.5 & 16.6 & 18.7 \\
\hline E12 & 12.2 & 15.5 & 15.8 & 16.3 & 17.1 & 28.7 \\
\hline E13 & 13.4 & 14.5 & 25.5 & 48.4 & 105.2 & 87.3 \\
\hline E14 & 9.1 & 10.3 & 20.4 & 45.6 & 95.1 & 90.4 \\
\hline E15 & 7.7 & 8.4 & 19.4 & 35.1 & 80.3 & 90.4 \\
\hline
\end{tabular}

can be concluded that for these emulsions, the effect of a variable amount of viscosity modifier was observed. The greater its quantity, the greater the stability of the system.

\section{Droplet size of emulsions}

It is commonly known that droplet size of the dispersed phase has a significant effect on emulsion stability, rheology, and optical properties (Kowalska et al. 2014). Monitoring the dispersed phase droplet size changes allows to assess the state of the emulsion, thereby determining the suitability of the product or the organoleptic in the case of food product. Based on the results of the average particle size of the tested emulsions, it was found that for all formulations, after $24 \mathrm{~h}$ from the preparation, this value was in the range of 4.2-14.8 $\mu \mathrm{m}$ (Table 2).

Analyzing the mean droplet diameter of the dispersed phase measured after $24 \mathrm{~h}$ from emulsion's preparation, it was observed that $50 \%$ of all particles had a diameter smaller than $10 \mu \mathrm{m}$ (Fig. 3). The narrowest particle size distribution and the smallest particle size were noted for emulsions E1, E2, and E3, based on modified fat containing predominant
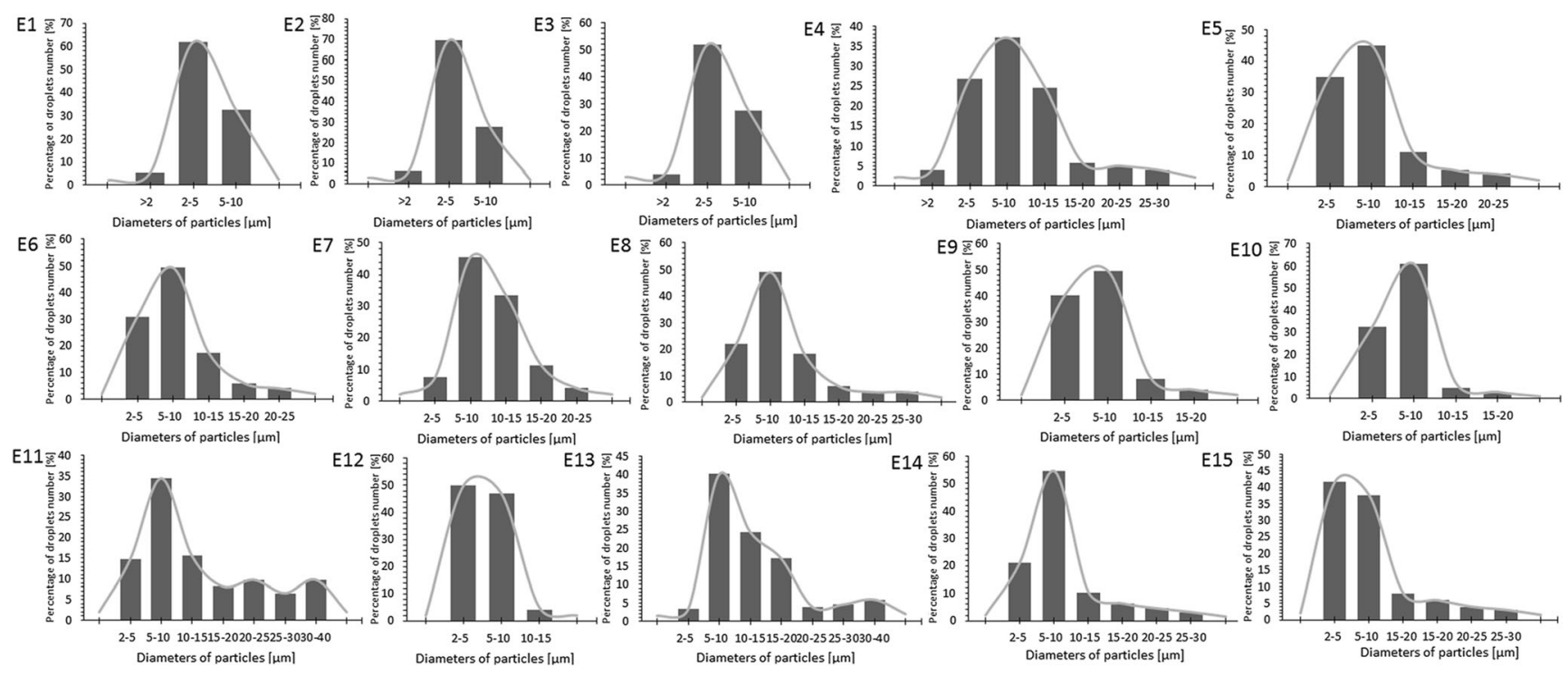

Diameters of particles $[\mu \mathrm{m}]$ Diameters of particles $[\mu \mathrm{m}]$
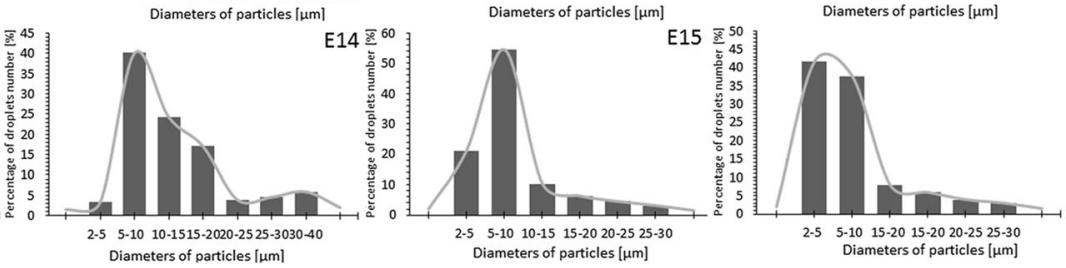

Fig. 3 Distribution of particle size emulsions E1-E15 $24 \mathrm{~h}$ after preparation 

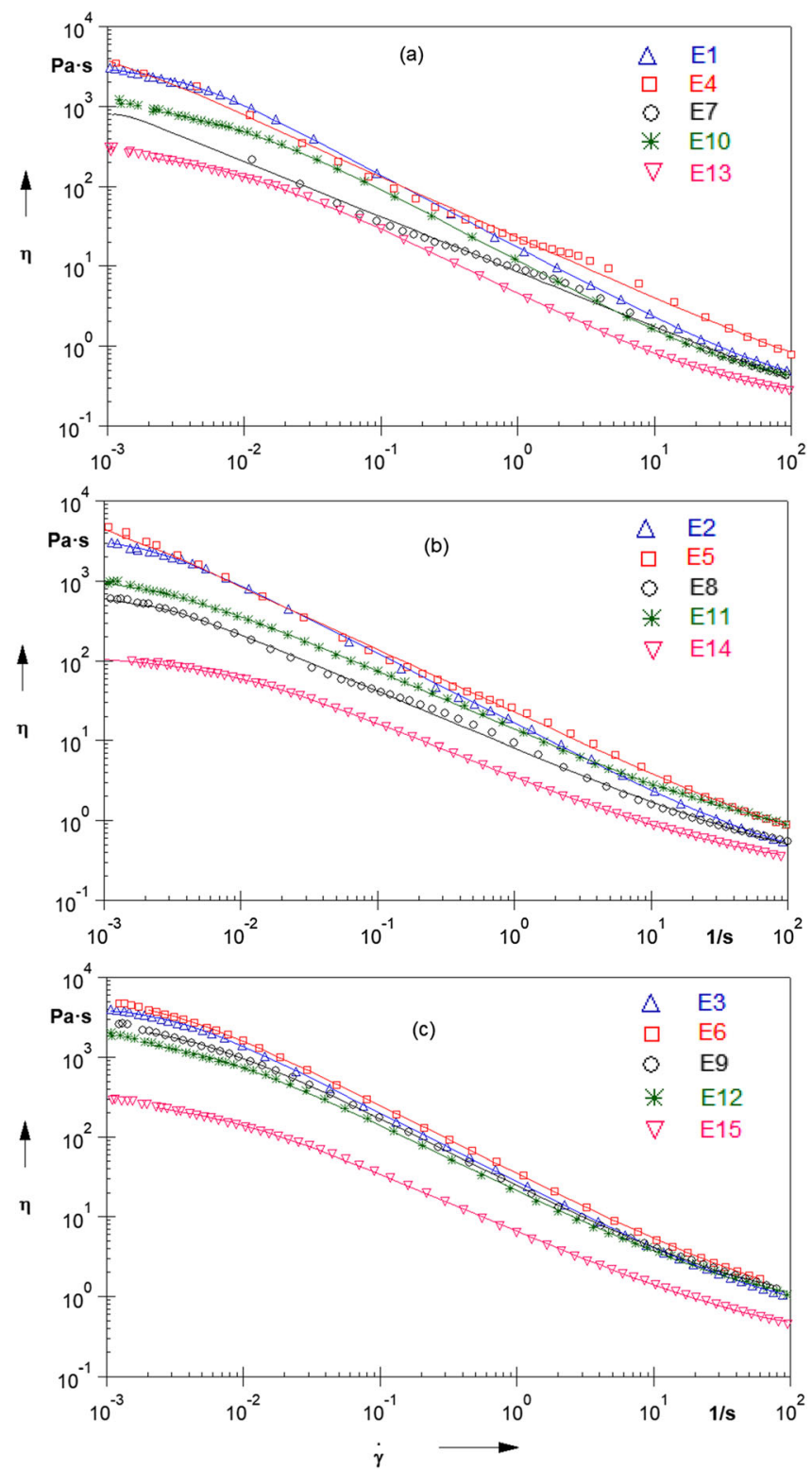

Fig. 4 Viscosity curves of the investigated emulsions containing various amounts of thickener (CMC) added: $0.6 \mathrm{wt} \%$ (a), $0.8 \mathrm{wt} \%$ (b), and $1 \mathrm{wt} \%$ (c). Measurements were performed at $20^{\circ} \mathrm{C}$. Solid lines represent the best fits of experimental data with the Carreau-Yasuda model

amounts of rabbit fat (Fig. 3, Table 2). These emulsions were the only ones revealing one fraction; i.e., they exhibited monodisperse character. Similar changes were observed by Kowalska et al. (2014) who also confirmed higher stability of the emulsion containing a higher proportion of animal fat (mutton tallow) with a smaller share of hemp oil. Observation of droplet morphology and measurement of their size and size distribution after prolonged storage period (1 month) confirmed negligible changes, which occurred in the mentioned systems and indicated high stability of investigated emulsions (Table 2). It has been shown that higher amounts of vegetable oil in the oil phase had a negative effect on emulsion stability resulting in the increase of the average droplet size. Thus, the greatest changes were observed for emulsions E13, E14, and
Table 3 Parameters of fits of the experimental data with the CarreauYasuda model

\begin{tabular}{lllllll}
\hline Emulsion & $\eta_{0}(\mathrm{~Pa} \mathrm{~s})$ & $\eta_{\infty}(\mathrm{Pa} \mathrm{s})$ & $a$ & $\lambda$ & $n$ & $R^{2}$ \\
\hline E1 & 3191.9 & 0.2298 & 1.4194 & 309.09 & 0.0864 & 0.9966 \\
E2 & 3795.2 & 0.2256 & 1.4214 & 511.69 & 0.1274 & 0.9980 \\
E3 & 4312.7 & 0.5195 & 1.4574 & 343.99 & 0.1311 & 0.9986 \\
E4 & 4468.7 & 0.3363 & 1.5678 & 476.52 & 0.1354 & 0.8909 \\
E5 & 2946.5 & 0.2634 & 8.1111 & 486.98 & 0.2126 & 0.9885 \\
E6 & 5932.1 & 0.6389 & 1.1919 & 409.62 & 0.1441 & 0.9999 \\
E7 & 1128.3 & 0.2841 & 3.6343 & 516.58 & 0.1930 & 0.9834 \\
E8 & 665.8 & 0.2259 & 1.6959 & 474.71 & 0.2801 & 0.9992 \\
E9 & 3067.7 & 0.7807 & 0.9637 & 283.72 & 0.1425 & 0.9993 \\
E10 & 1240.2 & 0.2786 & 0.8599 & 146.12 & 0.0623 & 0.9983 \\
E11 & 1376.1 & 0.4953 & 0.9283 & 495.27 & 0.2544 & 0.9997 \\
E12 & 1834.2 & 0.6796 & 1.1004 & 219.35 & 0.1686 & 0.9981 \\
E13 & 304.6 & 0.2002 & 0.8645 & 140.66 & 0.1457 & 0.9991 \\
E14 & 108.3 & 0.2315 & 1.0731 & 146.58 & 0.3009 & 0.9994 \\
E15 & 309.7 & 0.2685 & 0.9369 & 182.78 & 0.2543 & 0.9993 \\
\hline
\end{tabular}


E15. The particle diameter of these emulsions was within the range of $2-40 \mu \mathrm{m}$. The wide distribution of droplet size, the high droplet diameter, and the appearance of subsequent fractions (E13, three fractions; E14 and E15, two fractions) indicated insufficient stability of these systems. The appearance of additional fractions in these systems indicated the presence of larger particles, which over time can be combined into larger agglomerates. In this type of systems, there is a high possibility of destabilization processes such as creaming, flocculation, and coalescence (Dickinson 2009). Considering the average particle size of the emulsion (Table 2), it was observed that during the whole storage period, emulsions E13-E15 were characterized by the highest increase in the average particle size (72.6-91.2 $\mu \mathrm{m})$. The appearance of an additional fraction was observed in the remaining emulsions E4-E12. The particle size range was comparable and varied from 2 to $30 \mu \mathrm{m}$. However, the average particle size was not significantly variable in relation to the values measured during the subsequent weeks of storage of these emulsions. The least favorable droplet size distribution was definitely found in emulsion E11. Although the average particle size of this emulsion was within 13-14 $\mu \mathrm{m}$ and in the last week of the measurement $16.5 \mu \mathrm{m}$, the appearance of three separate fractions is clearly visible in Fig. 3. The particle size of this emulsion ranged from 2 to $40 \mu \mathrm{m}$ and it was the widest particle distribution for all tested dispersion systems. On the basis of the obtained results, it was also found that emulsions containing the same ratio of RF to PSO but different contents of viscosity modifier were characterized by the smaller average particle size with the higher content of CMC.
Fig. 5 Dependencies of storage $\left(\mathrm{G}^{\prime}\right)$ and loss $\left(\mathrm{G}^{\prime \prime}\right)$ moduli on the applied strain measured at constant angular frequency $1 \mathrm{rad} /$
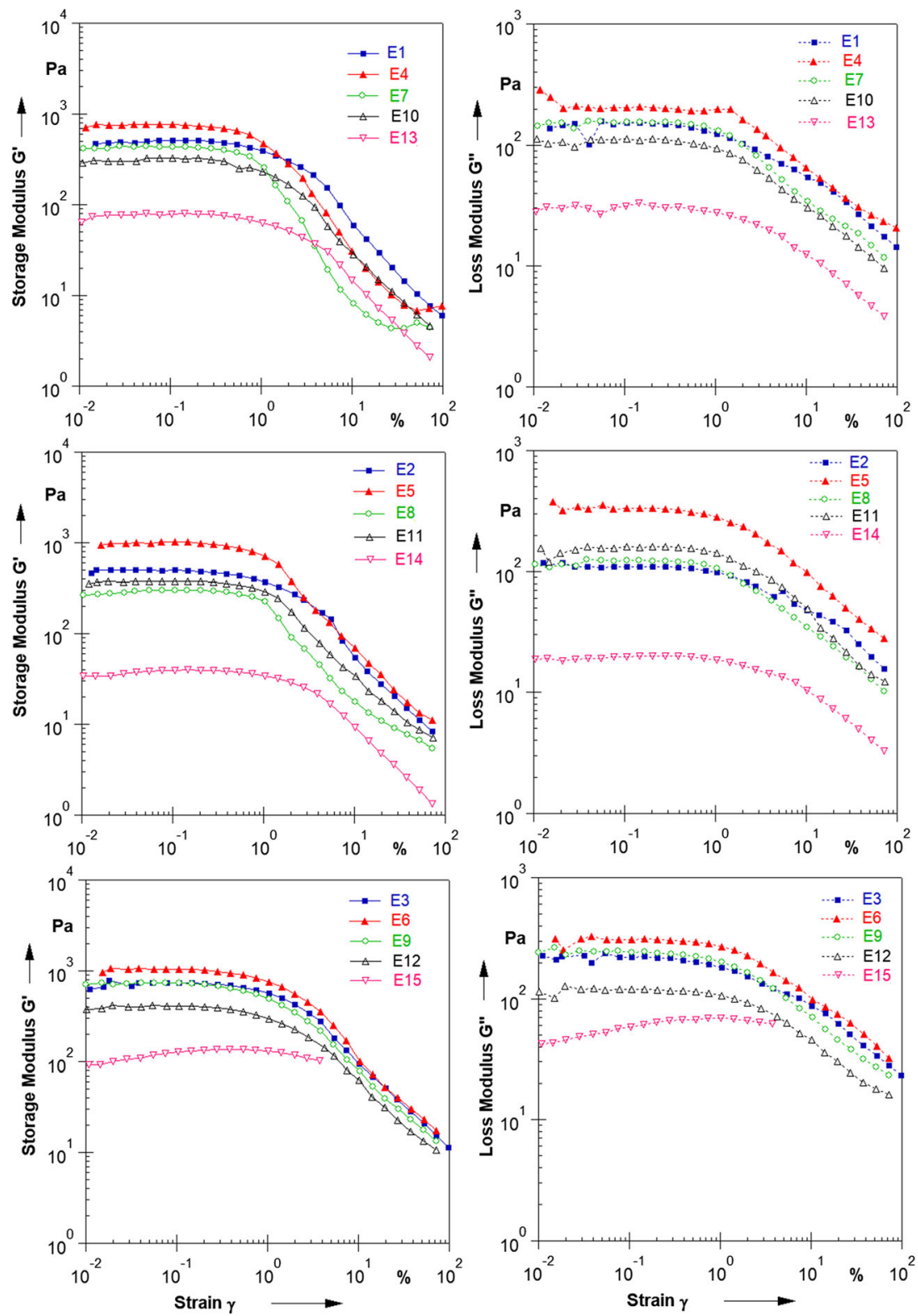
For most emulsions (E1-E12), the changes in particle size over time were characterized by a small increase $(0.5-$ $4.9 \mu \mathrm{m}$ ), which, according to Tzoumaki et al. (2011), means limited coalescence during storage period. Nevertheless, the largest particle size increase in the dispersed phase was observed for emulsions E13-E15, for which the increase after the 4-week storage period was over $70 \mu \mathrm{m}$. These values indicated significant changes in the system and are consistent with the previously presented results of delta backscattering (Fig. 1) and Turbiscan Stability Index (Fig. 2), which therefore confirm the greater destabilization of these systems during storage. Based on the presented results, it could be concluded that high content of pumpkin seed oil $(75 \%)$ in a fat base had a significant influence on the stability of the emulsion systems. For emulsions containing larger fraction of animal fat $(75: 25$, $60: 40$ ), a slight effect of the viscosity modifier on the increase of the average particle size was observed. This information is consistent with the authors who also obtained an increase in the size of this parameter during increasing amounts of the thickener (Paximada et al. 2016).

\section{Rheological behavior}

Shear-dependent rheological properties of the investigated emulsions have been measured to reveal their shear thinning behavior and study of zero shear viscosity dependence on the emulsion composition. The viscosity curves of the investigated emulsions, recorded at $20{ }^{\circ} \mathrm{C}$ in a controlled shear stress mode, are shown in Fig. 4.

The best fits of experimental data (marked with solid lines in Fig. 4) were obtained using a Carreau-Yasuda model for shear thinning fluids (Macosko 1994):

$\eta=\eta_{\infty}+\left(\eta_{0}-\eta_{\infty}\right) /\left[1+(\lambda \dot{\gamma})^{a}\right]^{(1-n) / a}$, where $\dot{\gamma}$ is the shear rate, $\eta_{0}$ is the zero shear viscosity, corresponding to the viscosity of the emulsion at shear rates approaching zero (lower Newtonian plateau). Parameter $\eta_{\infty}$ denotes an infinite shear viscosity illustrating viscous behavior of the system at high shear rate regime; $\lambda$ is a characteristic relaxation time of the studied system, the reciprocal $1 / \lambda$ characterizes the beginning of a shear thinning region, $(1-n)$ is the power law slope, and $a$ is a parameter that corresponds to the width of the transition between zero shear viscosity and shear thinning region. Parameters of fits with the Carreau-Yasuda equation are collected in Table 3 and marked with solid lines in Fig. 4.

All the investigated materials show shear thinning behavior characteristic for emulsion systems with the $\eta_{0}$ viscosity weakly dependent on the change of animal fat concentration in emulsions E1-E6, with larger amounts of this component in the oil phase. The smallest values of $\eta_{0}$ were observed for emulsions E13-E15, in which the oiling-off effect appeared. While comparing the emulsions containing the same amounts of thickening agent, it can be seen that the highest values of $\eta_{0}$ were obtained for emulsions E4, E5, and E6 in which the ratio of RF to PSO was 3:2. Changes of rheological properties with the amount of pumpkin seed oil in the interesterified fats are well consistent with $\triangle \mathrm{BS}$ and TSI measurements shown in Figs. 1 and 2. Shear thinning observed in our systems is a common feature of emulsions; however, a closer look to the viscosity profiles and the comparison of parameters obtained from fits of experimental data with the chosen rheological model (i.e., $\eta_{0}, \lambda, a$ ) for all the investigated systems tells much more about their consistency within a wide shear rate range and evidences well the effect of changing composition, i.e., the content of animal fat in the oil phase and the adjustment of the amount of thickener that enable optimization of the emulsion recipe and formation of a stable system of desired consistency.

Viscoelastic properties of the prepared emulsions were examined with small-strain amplitude oscillatory experiments. Linear viscoelastic (LVE) ranges and flow point parameters of the studied materials were estimated on the basis of strain dependencies of storage $\left(\mathrm{G}^{\prime}\right)$ and loss $\left(\mathrm{G}^{\prime \prime}\right)$ moduli, shown in Fig. 5. Parameters characterizing linear viscoelastic range as well as the maximum strain at flow point determined for all the studied systems are collected in Table 4.

Rheological tests revealed that emulsion E3 is the most stable among all the studied systems, with the widest LVE range indicating the formation of a stable gel-like microstructure at the low-strain region. Formation of similar microstructures, stabilized by weak van der Waals interactions and

Table 4 Linear viscoelastic (LVE) range and gel point parameters (G ' $=\mathrm{G}^{\prime \prime}, \tau$ and $\left.\gamma_{\max }\right)$ of the studied emulsions measured at a constant oscillation frequency

\begin{tabular}{lllrr}
\hline & & \multicolumn{3}{l}{ Gel point parameters } \\
\cline { 3 - 5 } Emulsion & LVE, strain $(\%)$ & $\mathrm{G}^{\prime}=\mathrm{G}^{\prime \prime}(\mathrm{Pa})$ & $\tau(\mathrm{Pa})$ & $\gamma_{\max }(\%)$ \\
\hline E1 & 0.737 & 52.2 & 8.68 & 11.73 \\
E2 & 0.407 & 45.58 & 7.86 & 12.15 \\
E3 & 0.918 & 81.67 & 13.76 & 11.88 \\
E4 & 0.255 & 108.44 & 6.59 & 4.28 \\
E5 & 0.236 & 164.86 & 9.81 & 4.20 \\
E6 & 0.364 & 96.94 & 14.70 & 10.71 \\
E7 & 0.211 & 95.53 & 2.95 & 2.17 \\
E8 & 0.241 & 70.04 & 2.71 & 2.73 \\
E9 & 0.317 & 59.66 & 11.17 & 13.23 \\
E10 & 0.340 & 32.83 & 4.14 & 8.89 \\
E11 & 0.293 & 90.27 & 4.68 & 3.65 \\
E12 & 0.377 & 28.59 & 8.77 & 21.67 \\
E13 & 0.499 & 10.82 & 2.11 & 13.77 \\
E14 & 0.620 & 11.93 & 1.34 & 7.98 \\
E15 & 0.187 & 32.18 & 13.11 & 10.54 \\
\hline
\end{tabular}


Fig. 6 Frequency sweeps of $\mathrm{G}^{\prime}$ and $\mathrm{G}^{\prime \prime}$ moduli recorded at constant strain $\gamma=0.1 \%$
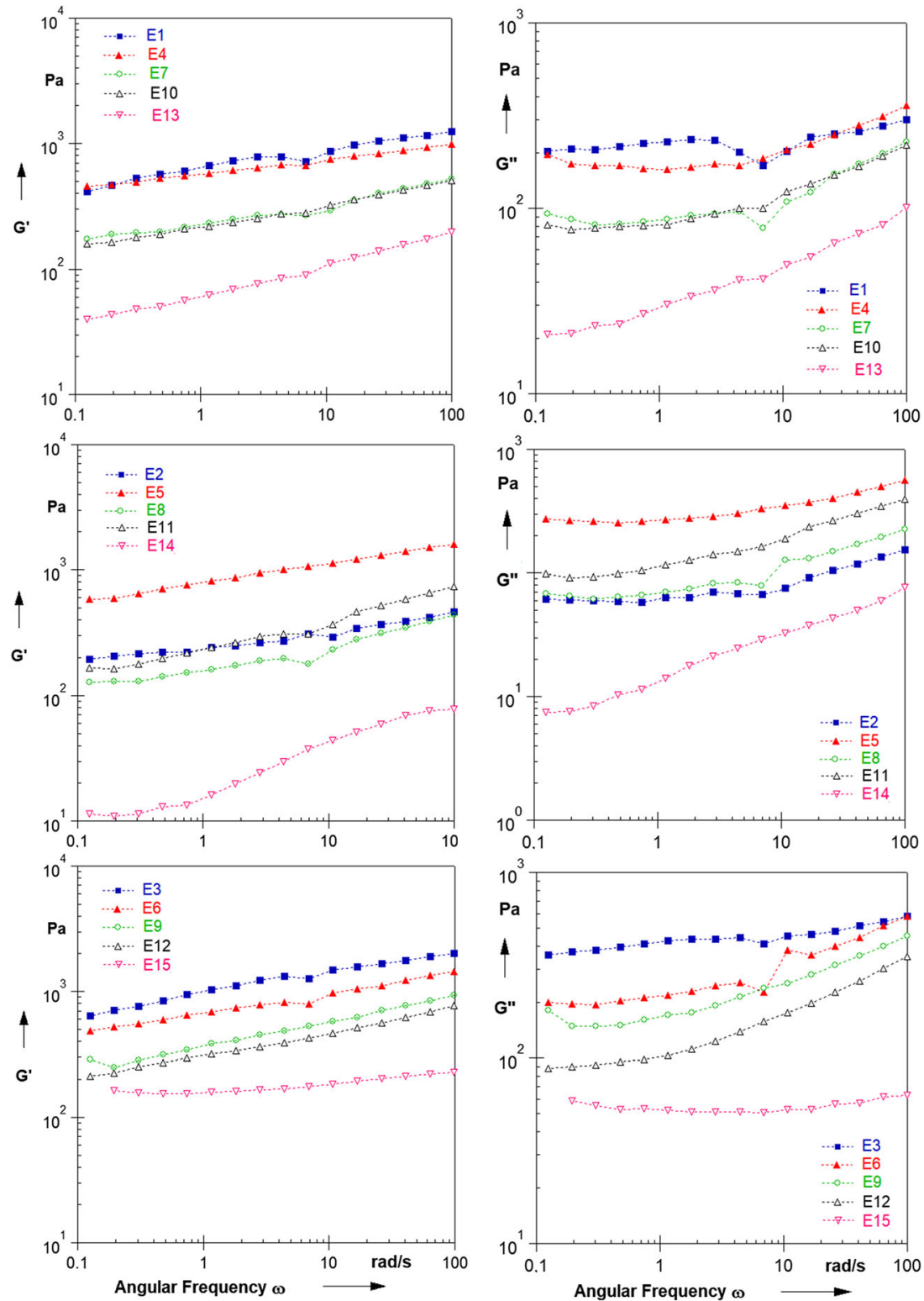

hydrogen bridges in foodstuff and their rheological behavior at flow conditions, is well consistent with the theoretical explanation of these phenomena given by Gabriele et al. (2001). We have shown that the prepared emulsions, especially those thickened with higher amounts of CMC, are characterized by enhanced toughness (higher values of $\mathrm{G}^{\prime}$ modulus) in the presence of shearing forces, which can be explained in terms of formation of an extended three-dimensional network at lowstrain regions. The investigated emulsions behave as typical deformation-dependent systems manifesting rather strong dependence of $\mathrm{G}^{\prime}$ and $\mathrm{G}^{\prime \prime}$ on the applied frequency, shown in Fig. 6. Behavior of emulsion E15 deviates from the general tendency as in this case at low frequency range, the values of both mechanical moduli do not change significantly with applied frequency. The upward deflection of both curves indicates the larger tendency of this emulsion to destabilization, most probably by creaming or other processes.

\section{Conclusions}

Emulsion E3 containing $75 \%$ of rabbit fat, $25 \%$ of pumpkin seed oil, and $1 \mathrm{wt} \%$ of viscosity modifier was characterized by the highest stability. The average particle size of this emulsion did not change significantly during the entire storage period and the Turbiscan test as well as the TSI value did not show any significant changes indicating the destabilization process. Emulsions based on modified blends containing $75 \%$ pumpkin seed oil were unstable systems. These emulsions were characterized by the highest value of the delta BS parameter 
and also the largest increase in particle size during the 1month storage period. The work also confirmed that for systems containing a higher percentage of animal fat, the addition of a thickener had a positive effect on the stability of dispersion systems.

The research confirmed the possibility of producing structured fat which can be the basis for new emulsion systems proposed both as a food product and as a basis for care products of the cosmetics industry or even as an ingredient in dermocosmetics because the ingredients present in the resulting product are compatible with the human skin.

Funding information This work was supported by the Kazimierz Pulaski University of Technology and Humanities in Radom and by statutory budget of Faculty of Chemistry, Warsaw University of Technology.

Open Access This article is licensed under a Creative Commons Attribution 4.0 International License, which permits use, sharing, adaptation, distribution and reproduction in any medium or format, as long as you give appropriate credit to the original author(s) and the source, provide a link to the Creative Commons licence, and indicate if changes were made. The images or other third party material in this article are included in the article's Creative Commons licence, unless indicated otherwise in a credit line to the material. If material is not included in the article's Creative Commons licence and your intended use is not permitted by statutory regulation or exceeds the permitted use, you will need to obtain permission directly from the copyright holder. To view a copy of this licence, visit http://creativecommons.org/licenses/by/4.0/.

\section{References}

Anton N, Vandamme TF (2011) Nano-emulsions and microemulsions, clarifications of the critical differences. Pharm Res 28:978-985

Celia C, Trapasso E, Cosco D, Paolino D, Fresta M (2009) Turbiscan Lab® Expert analysis of the stability of ethosomes ${ }^{\circledR}$ and ultradeformable liposomes containing a bilayer fluidizing agent. Colloids Surf B: Biointerfaces 72:155-160

De Graef V, Vereecken J, Smith KW, Bhaggan K, Dewettinck K (2012) Effect of TAG composition on the solid fat content profile, microstructure, and hardness of model fat blends with identical saturated fatty acid content. Eur J Lipid Sci Technol 114(5):592-601

Dickinson E (2009) Hydrocolloids as emulsifiers and emulsion stabilizers. Food Hydrocoll 23:1473-1482

Gabriele D, Cindio B, D'Antona P (2001) A weak gel model for foods. Rheol Acta 40:120-127

Kowalska M (2016) Physical stability and the distribution of droplets in rice oil water based emulsions. J Dispers Sci Technol 37(2):222-230

Kowalska M, Żbikowska A, Śmiechowski K, Marciniak-Łukasiak K (2014) Wpływ ilości lecytyny słonecznikowej i czasu homogenizacji na stabilność emulsji spożywczej zawierającej olej z orzechów włoskich. Żywność Nauka Technologia Jakość 1(92):78-91

Kowalska M, Woźniak M, Tavernier S, Żbikowska A, Pazdur L (2018) Assessment of the effectiveness of synthetic diacylglycerols as emulsifiers in dispersion systems containing interesterified turkey fat. Eur Food Res Technol 244(9):1665-1674

Kowalska M, Woźniak M, Krztoń-Maziopa A, Tavernier S, Pazdur Ł, Zbikowska A (2019) Development of the emulsions containing modified fats formed via enzymatic interesterification catalyzed by specific lipase with various amount of water. J Dispers Sci Technol 40(2):192-205

Kraai GN, Winkelman JGM, De Vries JG, Heeres HJ (2008) Kinetic studies on the Rhizomucor miehei lipase catalyzed esterification reaction of oleic acid with 1-butanol in a biphasic system. Biochem Eng J 41(1):87-94

Lim JS, Wong SF, Law MC, Samyudia Y, Dol SS (2015) A review on the effects of emulsions on flow behaviours and common factors affecting the stability of emulsions. J Appl Sci 15(2):167-172

Liu J, Huang XF, Lu LJ, Li MX, Xu JC, Deng HP (2011) Turbiscan Lab® Expert analysis of the biological demulsification of a water-in-oil emulsion by two biodemulsifiers. J Hazard Mater 190:214-221

Macosko CW (1994) Rheology, principles, measurements and applications. Wiley-VCH, New York

McClements DJ (2007) Critical review of techniques and methodologies for characterization of emulsion stability. Crit Rev Food Sci Nutr 47(7):611-649

McClements DJ, Rao J (2011) Food-grade nanoemulsions: formulation, fabrication, properties, performance, biological fate, and potential toxicity. Crit Rev Food Sci Nutr 51(4):285-330

Paolino D, Stancampiano AHS, Cilurzo F, Cosco D, Puglisi G, Pignatello R (2011) Nanostructured lipid carriers (NLC) for the topical delivery of lutein. Drug Deliv Lett 1:32-39

Paximada P, Koutinas AA, Scholten E, Mandala IG (2016) Effect of bacterial cellulose addition on physical properties of WPI emulsions. Comparison with common thickeners. Food Hydrocoll 54:245-254

Piorkowski DT, McClements DJ (2013) Beverage emulsions: recent developments in formulation, production, and applications. Food Hydrocoll 42:5-41

Subroto E (2020) Monoacylglycerols and diacylglycerols for fat-based food products: a review. Food Res 4(4):932-943

Sztukowski DM, Harvey W Yarranton, (2005) Oilfield solids and waterin-oil emulsion stability. J Colloid Interface Sci 285: 821-833

Tang JT, Quinlan PJ, Tam KC (2015) Stimuli-responsive pickering emulsions: 782 recent advances and potential applications. Soft Matter 11:3512-3529

Turbiscanlab instruction (2013) User manual for the device and TurbiSoft 2.0.0.33 program. Formulaction SA, L’Union

Tzoumaki MV, Moschakis T, Kiosseoglou V, Biliaderis CG (2011) Oilin-water emulsions stabilized by chitin nanocrystal particles. Food Hydrocoll 25:1521-1529

Wiśniewska M (2010) Influences of polyacrylic acid adsorption and temperature on the alumina suspension stability. Powder Technol 198(2):258-266

Wiśniewska M, Urban T, Nosal-Wiercińska A, Zarko V, Gun'ko V (2014) Comparison of stability properties of poly (acrylic acid) adsorbed on the surface of silica, alumina and mixed silica-alumina nanoparticlesapplication of turbidimetry method. Open Chem 12:476-479

Xu D, Zhang J, Cao Y, Wang J, Xiao J (2016) Influence of microcrystalline cellulose on the microrheological property and freeze-thaw stability of soybean protein hydrolysate stabilized curcumin emulsion. LWT-Food Sci Technol 66:590-597

Zou L, Akoh CC (2013) Characterisation and optimisation of physical and oxidative stability of structured lipid-based infant formula emulsion: effects of emulsifiers and biopolymer thickeners. Food Chem 141(3):2486-2494

Publisher's note Springer Nature remains neutral with regard to jurisdictional claims in published maps and institutional affiliations. 